\title{
The assessment of Bioactivators effectiveness used for the Household Waste Water Treatment
}

\author{
O.G. Selivanov ${ }^{1}$, E.S. Pikalov ${ }^{2}$, A.S. Kolosova ${ }^{3}$ \\ ${ }^{1}$ Vladimir State University named after A. G. and N. G. Stoletovs, Vladimir, Russian Federation, \\ selivanov6003@mail.ru \\ ${ }^{2}$ Vladimir State University named after A. G. and N. G. Stoletovs, Vladimir, Russian Federation, \\ evgeniy-pikalov@mail.ru \\ ${ }^{3}$ Vladimir State University named after A. G. and N. G. Stoletovs, Vladimir, Russian Federation, \\ anastasiya_kolosova_777@mail.ru
}

\begin{abstract}
The research presents the assessment results of various bioactivators effectiveness used with or without aeration in the domestic wastewater treatment. The studies were conducted using the model aqueous solutions where organic contaminants contentwas imitated by the mixture of starch, sucrose and milk powder. The effectiveness of various bioactivators was evaluated by reducing chemical oxygen consumption indicator during the experimental studies. It was revealed that bacteria contained in the studied bioactivators are aerobic and gram-positive, and bioactivators effectiveness increases by 8-15\% on average if used with the aeration. The recommendations are given for the studied bioactivators application in the domestic waste water treatment under various operating conditions.
\end{abstract}

Key words: Household waste water, organic contaminants, biologic treatment, bioactivators, chemical oxygen consumption, aerobic microorganisms, aeration

\section{INTRODUCTION}

The household waste water is formed directly in the result of human domestic activities: cooking, dishwashing, cleaning, washing, personal hygiene, etc. In this regard, the contaminants in the waste water are represented basically by organic substances and biogenic elements, so in most cases mechanical, sorption and biological treatment methods are applied in autonomous sewer systems for the household wastewater disposal and treatment [1-6]. The most common and effective methods, especially for highly concentrated wastewater, are methods including sequential or combined aerobic and anaerobic treatment stages $[7,8]$.

For the autonomous treatment systems the most effective equipment is the aerobic septic tank, which is a multistage equipment (see figure 1).The first section is used for the effluents mechanical treatment including anaerobic sludge digestion. The second section includes aerobic treatment with the aeration by the air supplied from atmosphere via compressor, and finally the water is additionally clarified, filtered and drained or discharged directly into the sewage after aerobic treatment.

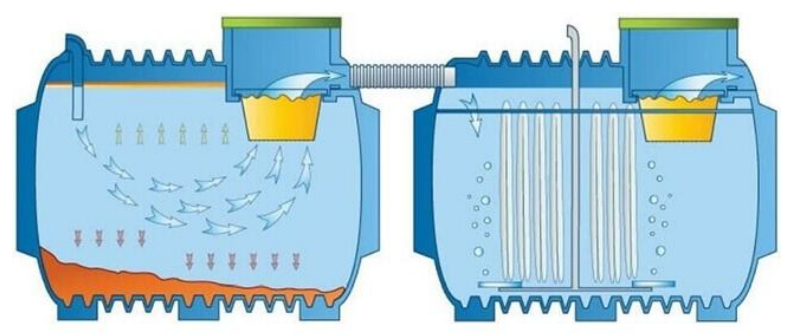

Figure 1: Aerobic septic tank operation diagram

Anaerobic digestion and aerobic treatment are known to be based on the microorganism activity mineralizing dissolved organic compounds which are their nutrient source. In natural environment the process of biological treatment is quite slow, since the number of bacteria in wastewater is not enough for active fermentation of household waste. Moreover the degree of biological treatment intensity depends on the composition and concentration of organic substances in wastewater, on the wastewater treatment duration, the treatment equipment design, temperature conditions, the species composition of microorganisms, their adaptive abilities, resistance to certain toxic contaminants, etc.

To intensify the growth the microorganisms population and the processes of biological wastewater treatment, the methods of nutrients additional introduction into the water or joint introduction of microorganisms and nutrients as a part of bioactivators are widely used [9-11]. Bioactivators are specially derived micro-organisms, or support to these micro-organisms, improving the operation of septic tanks, increasing the efficiency of organic substances decomposition in wastewater and unpleasant odor removal. Bioactivators contain enzymes promoting the breakdown of proteins, fats and carbohydrates, such as amylase, peptidase, lipase, lactase, etc. The effective application of bioactivators requires their correct selection for the specific organic contaminants and the creation of favorable environment for microbial communities. 
The research objective was to evaluate the effectiveness of various bioactivators used for the household wastewater treatment containing organic contaminants with or without aeration via laboratory modeling method.

\section{RESEARCH OBJECTS AND METHODS}

The three common brands of bioactivators were selected for the experiments: "Doctor Robic" brand 109, "Biobac" brand BB-YS 060 and bioactivator brand "Sanex".

The model solutions simulating domestic wastewater containing organic contaminants were prepared from the following components:

- starch $\left(\mathrm{C}_{6} \mathrm{H}_{10} \mathrm{O}_{5}\right)_{\mathrm{n}}$ in compliance with GOST 53876-2010, used to model complex carbohydrates in household wastewater. It is a mixture of amylose and amylopectin polysaccharides with alpha-glucose as amonomer;

- sucrose $\left(\mathrm{C}_{12} \mathrm{H}_{22} \mathrm{O}_{11}\right)$ of "Ch.d.a." brand in compliance withGOST 5833-75, used to model simple carbohydrates in household wastewater. It is disaccharide from oligosaccharide group, consisting of two monosaccharides: $\alpha$-glucose and $\beta$-fructose;

- rich milk powder in compliance withGOST 33629-2015, was used to model protein, fat and simple carbohydrates in household wastewater.

All of the above organic compounds are microorganisms nutrients avaialble in bioactivators, and, therefore, microorganisms can remove them from the model solutions simulating domestic wastewater. The treatment efficiency of organic compounds removal from model solutions was estimated arrording the decrease in their chemical oxygen consumption (COD) duringthe experiments. The photometric COD analyzer "Expert-003COD" was used for measuring. To study the aeration effect on the biological purification process intensification in themodel solutions, air oxygen was supplied by the compressor with a capacity of $0.12 \mathrm{~m}^{3} / \mathrm{h}$. All experiments were performed static at ambient temperature of $22 \pm 2{ }^{\circ} \mathrm{C}$. Sampling was repeated 3 times on the fourth, eighth and twelfth days. The initial COD was determined before adding bioactivators into the model solutions.

The model solutions were prepared using distilled water. The mixture of starch, sucrose and milk powder in equal quantities with a total concentration of $5.1 \mathrm{~g} / \mathrm{l}$ was added into the water. To study the microorganisms contained in the applied specimen, bioactivators suspensions were diluted in sterile distilled water, and then dispensed in Petri dishes for surface planting using meat-peptone agar as nutrient medium. The resulting specimen smears were stained using Gram method, dried, and microscopized using the immersion system (x100 lens) on Micros MC-20 microscope. To assess bacteria viability the associations, resulting in surface planting from the model solutions on the fourth day from the experiment, were similarly microscopized.

\section{RESEARCH RESULTS AND DISCUSSION}

After the surface planting of microorganisms from the studied bioactivators and after two - three incubation days in thermostat, microorganisms growth was visible on the nutrient medium surface, both in the case of sampling from distilled water and in the case of sampling from model solutions (see figure 2 , a). It indicates that the bacteria in each of the studied bioactivators are viable and in the process of organic component consumption in the model solutions, they remain active, and the total number of microbial cells increases. Herewith, no oppression was found in the result of aeration, and therefore, microbial cells are aerobic.

In the studied specimen of all three bioactivators, bacterial associations were detected, colored in blue-purple, thus allowing to attribute them to gram-positive bacteria with a single-layer cell membrane (see figure $2, \mathrm{~b}$ ). The studies have shown that microbial associations of the studied bioactivators contain bacteria cultures of different morphologies, but are mainly represented by different sizerods and cocci, chains of cocci (Streptococcus), single cocci (micrococcus), and besides rod-shaped bacteria (Bacillus) have also been revealed.

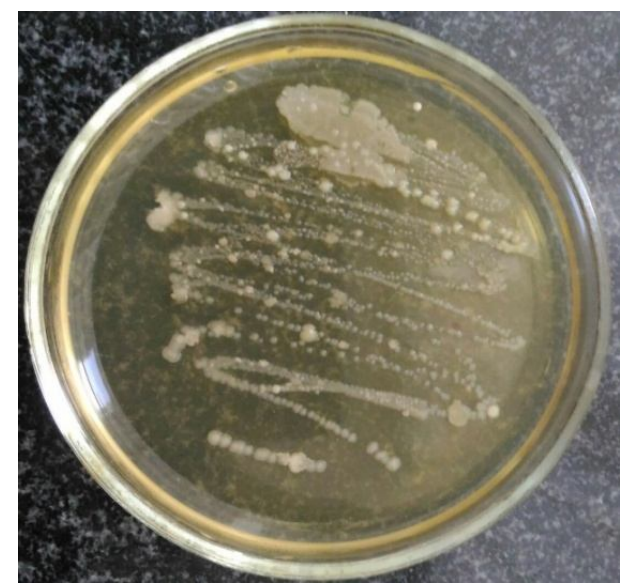

a)

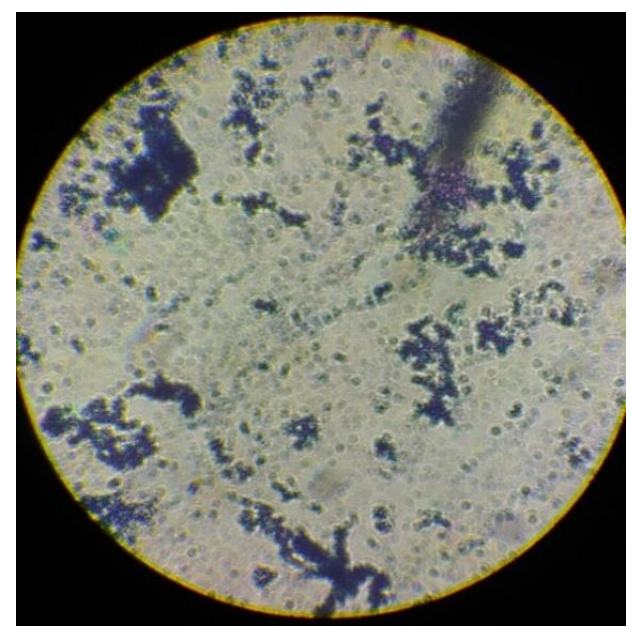

b)

Figure2. Microorganisms study using "Doctor Robic "bioactivator:

a) microorganisms growth on the nutrient medium in two incubation days;

b) coloring results of bacterial associations according to Gram planting method. 
At the second research stage the bioactivators efficiency has been assessed in the treatment process of model solutions, containing a mixture of organic substances, with and without aeration.

The treatment results of the considered model solution containing the mixture of organic contaminants using "Doctor Robic" bioactivator with and without aeration are shown in figure 3.

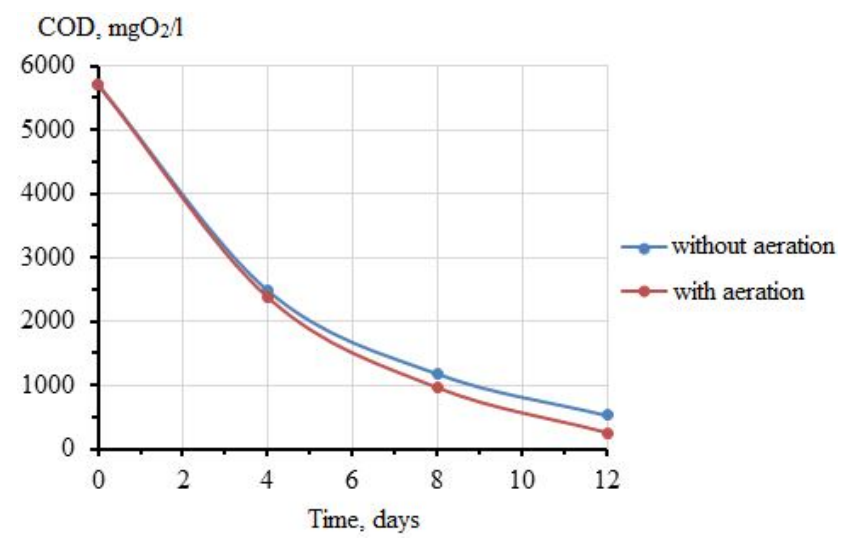

Figure 3:Treatment efficiency of model solution containing the mixture of the considered contaminants using "Doctor Robic" bioactivator.

The presented data proves that during the treatment of organic contaminants mixture, high and uniform treatment intensity is observed. The total COD decrease amounted about $90.8 \%$ of the original value without aeration and about $95.6 \%$ with aeration.

The treatment results of the model solution containing the considered organic contaminants mixture using «Biobac» bioactivator with aeration and without aeration are shown in figure 4 .

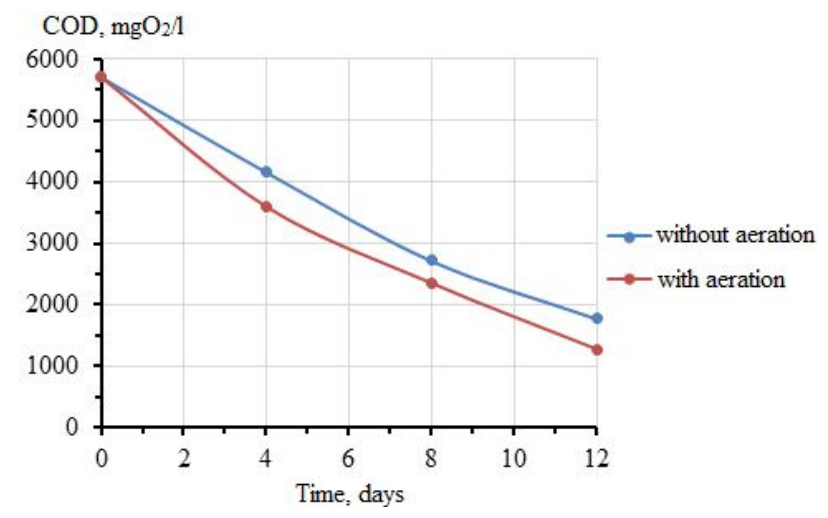

Figure 4:Treatment efficiency of the model solution containing the mixture of organic contaminants using "Biobac" bioactivator

In this case, similar linear COD decrease and more effective treatment is observed during aeration. The total COD decrease was about $69 \%$ of the original value without aeration and about $77.9 \%$ with aeration.

The treatment results of the model solution containing the mixture of organic contaminants using "Sanex" bioactivator without aeration and with aeration are demonstrated in figure 5.

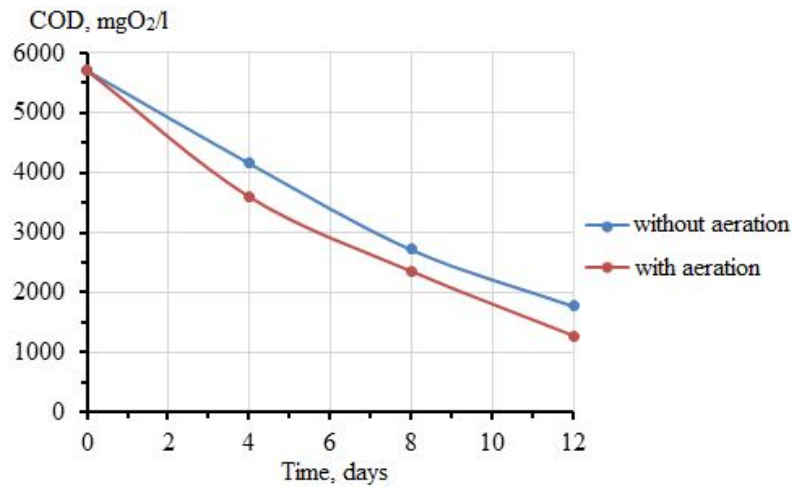

Figure 5:Treatment efficiency of the model solution containing the mixture of organic contaminants using "Sanex" bioactivator

The presented data show uniform and insignificant COD decrease, herewith the process intensity increases during aeration. The total COD decrease was about $54.7 \%$ of the original value without aeration and about $71.2 \%$ with aeration. Bioactivators comparison revealed that "Doctor Robic" bioactivator demonstrated the best results.

\section{CONCLUSION}

The research results proved thet the studied bioactivators composition includes gram-positive aerobic bacteria, which use organic contaminants as nutrient medium for their sustenance.During the treatmentof model solutions, imitating household waste waterwith the studied bioactivators, the aeration was stated to increase the treatment efficiency by8-15\% on average.According to the research results, the aeration can be recommended for improvingbioactivators efficiency, which create better conditions for the long-term functioning of the biologically active system and thereby improving the organic component mineralization in the domestic wastewater.

\section{REFERENCES}

1. V.Yu. Chukhlanov, O.G. Selivanov, E.S. Pikalov, S.M. Chesnokova, A.A. Podolets'Purification of waterfrom fluoride ions by a lanthanum-containing ceramic material.'Ecology and Industry of Russia. 2018, Vol. 22, № 8, pp. 28-31. https://doi.org/10.18412/1816-0395-2018-8-28-31

2. N.B. Singh, G. Nagpal, S. Agrawal, Rachna"Water purification by using Adsorbents: A Review."Environmental Technology \& Innovation. 2018, Vol. 11, pp. 187-240.

3. O.G. Selivanov, E.S. Pikalov, A.S. Kolosova"Ceramic material for fluoride and phosphate ions removal from natural water.'International Journal of Emerging Trends in Engineering Research. 2020, Vol.8, № 5, pp. 1732 1735 .

https://doi.org/10.30534/ijeter/2020/39852020

4. T.A. Trifonova, A.A. Povorov, L.A. Shirkin, O.G. Selivanov, M.E. Ilina “Optimization of membrane 
reverse osmosis separation for aqueous media characterized by high mineralization.'International Journal of Emerging Trends in Engineering Research. 2020, Vol. 8, № 4, pp. 1125-1128.

https://doi.org/10.30534/ijeter/2020/28842020

5. T.A. Trifonova, S.I. Roschina, L.A. Shirkin, O.G. Selivanov, M.E. Ilina"An integrated innovative technology for the treatment of municipal solid waste landfill leachate.'Biosciences Biotechnology Research Asia. 2015, Vol.12, № 3, pp. 2481-2488.

6. H. Shen, X. Chen, D. Zhang, H. Chen "Generation of soluble microbial products by bio-activated carbon filter during drinking water advanced treatment and its influence on spectral characteristics." Science of The Total Environment, 2016, Vol. 569-570, pp.1289-1298.

https://doi.org/10.1016/j.scitotenv.2016.06.205

7. Y.J. Chan, M.F. Chong, C.L. Law D.G. Hassell "A review on anaerobic-aerobic treatment of industrial and municipal wastewater." Chemical Engineering Journal. 2009, Vol. 155, № 1-2, pp. 1-18. https://doi.org/10.1016/j.cej.2009.06.041

8. G. Kassab, M. Halalsheh, A. Klapwijk, M. Fayyad. J.B. van Lier "Sequential anaerobic-aerobic treatment for domestic wastewater - A review."Bioresource Technology. 2010, Vol. 101, № 10, pp. 3299-3310.

https://doi.org/10.1016/j.biortech.2009.12.039

9. S. Doni, C. Macci, C. Martinelli, R. Iannelli, P. Brignoli, S. Lampis, M. Andreolli, G. Vallini, G. Masciandaro "Combination of sediment washing and bioactivators as a potential strategy for dredged marine sediment recovery."Ecological Engineering. 2018, Vol.125, pp. 26-37. https://doi.org/10.1016/j.ecoleng.2018.10.009

10. F. Crisafi, M. Genovese, F.Smedile, D.Russo, M.Catalfamo, M.Yakimov, L.Giuliano, R.Denaro "Bioremediation technologies for polluted seawater sampled after an oil-spill in Taranto Gulf (Italy): A comparison of biostimulation, bioaugmentation and use of a washing agent in microcosm studies."Marine Pollution Bulletin. 2016, Vol. 106, № 1-2, pp.119-126. https://doi.org/10.1016/j.marpolbul.2016.03.017

11. V. Blonskaja, A. Menert, R. Vilu "Use of two-stage anaerobic treatment for distillery waste." Advances in Environmental Research. Vol. 7, № 3, pp. 671-678. https://doi.org/10.1016/S1093-0191(02)00038-2 